\title{
Role of various coloring pigments within different varieties of carrot (Daucus carota)
}

\begin{abstract}
The diversity in color among fruits and vegetables is immense and the primary reason for such diversification is presence of different types of colorants or pigments. The difference in molecular structure of pigments particularly in conjugation determines the overall hue and generally more the conjugation within a molecule more its color intensity. Chlorophylls, carotenoids and anthocyanins are major classes of pigments associated with the color of fruits and vegetables, and the presence of latter two is more dominant in fruits. $\alpha$-carotene, $\beta$-carotene, lycopene, etc. belong to carotene class of carotenoids whereas lutein and zeoxanthin are oxygenated forms of carotenoids. Anthocyanins along with carotenoids are present widely in carrots and by virtue of its presence the roots a lot of diversity in color ranging from white to black \& red to yellow. Majorly the molecules of such pigments have been reported to have numerous health benefits due to their radical or atomic oxygen scavenging activity. The provitamin A activity of $\alpha$ - and $\beta$-carotene further impart the functionality of carrots.
\end{abstract}

Volume 8 Issue 5 - 2018

\author{
Raees-ul Haq, Kamlesh Prasad \\ Department of Food Engineering and Technology, SantLongowal \\ Institute of Engineering \& Technology, India
}

\begin{abstract}
Correspondence: Raees-ul Haq, Department of Food Engineering and Technology, SantLongowal Institute of Engineering \& Technology, Punjab India, Tel +91-9478154990, Email raeeswani@gmail.com
\end{abstract}

Received: November 15, 2017| Published: September 27, 2018

Keywords: carrot, $\alpha$-carotene, $\beta$-carotene, anthocyanin, chlorophyll, lycopene

\section{Introduction}

Fruits and vegetables are important source of bioactive components in addition to the appreciable portions of basic nutrients needed for the normal development and functioning of human body. The presence of bioactive components has shifted the research towards the identification and isolation of such compounds. In addition to variation of such compounds within different types of agricultural products, a considerable difference in plant secondary metabolites is found even in products sharing a common genus. Variation of agricultural practices in form of seasonal cultivation, location of cultivation, etc. has a profound role in misbalancing the level of bioactive components even within same variety. ${ }^{1}$ Different varieties of almost all cultivated crops have evolved, naturally or scientifically, containing distinctive compounds in good proportions. A lot of fruits and vegetables are now available in more than one color and their identity as regarded on basis of a particular color may sooner be a misnomer. The varietal difference in fruits and vegetables such as carrot, apples, raspberries, etc. have given rise to a totally new batch of products with different colored entities like the individual colors of rainbow. Carrot roots are highly nutritious and contain appreciable amounts of minerals and bioactive components. ${ }^{2}$ Carrots are regarded as the unique root vegetables that have presence of carotenoids within their tissues. The plants are mainly grown in temperate regions around the globe all year round and seasonally in subtropics prior to winter season. The roots are nutritious and are among few vegetables that can be eaten without any processing.

The presence of carotenoids that is precursor of vitamin A elevates its significance among other vegetables. Carrots are also rich sources of fiber, potassium, phosphorus and sodium, all of which are very important for the normal functioning of human body. Antioxidant activity of carrots is conferred by the presence of different bioactive components particularly ascorbic acid and carotenoids. ${ }^{3}$ Some dark varieties of carrots have also hefty proportions of plant phenolics in form of anthocyanins that has led to position it at rank six as per Chu et al., ${ }^{4}$ Alcoholic compounds in form of aliphatic polyacetylene (C17) known as falcarinol has also been discovered in carrots along with its two more forms as falcarindiol and falcariniol- 3 acetate. ${ }^{5}$ Carotenoid pigments are known to protect the plant cells from photosensitization by acting as accumulators of natural light. ${ }^{6}$ Presence of colorants in carrot impart the roots with yellow, orange, black, red, purple and white color (Figure 1) depending upon the presence of major compound as both groups (carotenoids and anthocyanins) constitute a very vast cluster of compounds. The class of carotenoids is mainly differentiated into hydrocarbon isoprenoid units known as carotenes and its oxygenated forms termed as xanthophylls. Anthocyanins are largest group of water soluble pigments that impart purple, red, black or blue color to various agriculture products particularly in fruits, and the basic structure consists of anthocyanidins that in association with a sugar molecule is recognized as anthocyanin. ${ }^{1}$ Lycopene, $\alpha$-carotene, $\beta$-carotene, etc. are sub categories of carotenes while as lute in and zeoxanthin belong to xanthophylls. ${ }^{7,8}$ In general among all different types of carotenoids, presence of $\beta$-carotene dominates in almost all varieties by more than half concentration followed by $\alpha$-carotene, lutein and other minor carotenoids. ${ }^{9}$ Dehydration of carrots. ${ }^{10,11}$ is related to losses in bioactive components and losses can be lowered down by adopting proper procedures. ${ }^{12}$

The presence of higher proportions of anthocyanins particularly acylated cyaniding provides black or purple color to the carrots. Orange color of carrots is governed by large quantities of $\beta$-carotene while as the presence of lycopene in hefty concentrations give a solid red color to the roots. In Yellow colored carrots lutein predominates as the major carotenoid whereas white colored carrots are mainly devoid of $\alpha$-carotene and lycopene. White varieties are known to contain smaller traces of lutein and $\beta$-carotene. ${ }^{1}$ The photo-protection attribute of carotenoids in photosynthesis is due to its quenching ability of atomic oxygen generated during the process. ${ }^{13}$ The key to such process lies in basic structure of molecule as the conjugation of double bonds effectively act as oxygen scavengers, thereby inhibiting lipid peroxidation in cells. ${ }^{14}$ Physiological activity of $\alpha$ and $\beta$-carotene as provitamin $\mathrm{A}$ is $50 \%$ and $100 \%$, respectively, with latter developing into two molecules of retinol. The number of conjugated double bonds 
determines the overall hue, as one less conjugation in $\alpha$-carotene is fader in color than $\beta$-carotene. The number of double bonds is further up by number two within lycopene molecule therefore products with such molecules are more brighter color. ${ }^{1}$ The degradation of chlorophyll in autumn season perceives the presence of oxygenated carotenes that are otherwise masked by brighter green colored chlorophylls. ${ }^{15}$

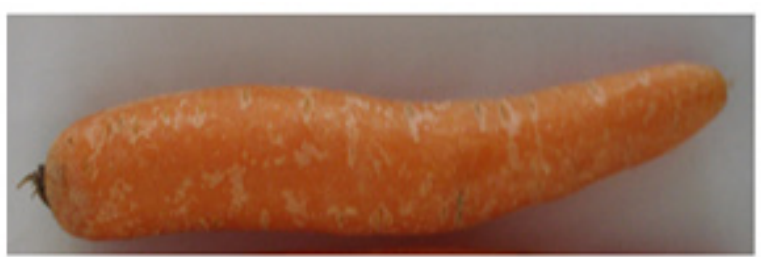

Orange Colored Carrot
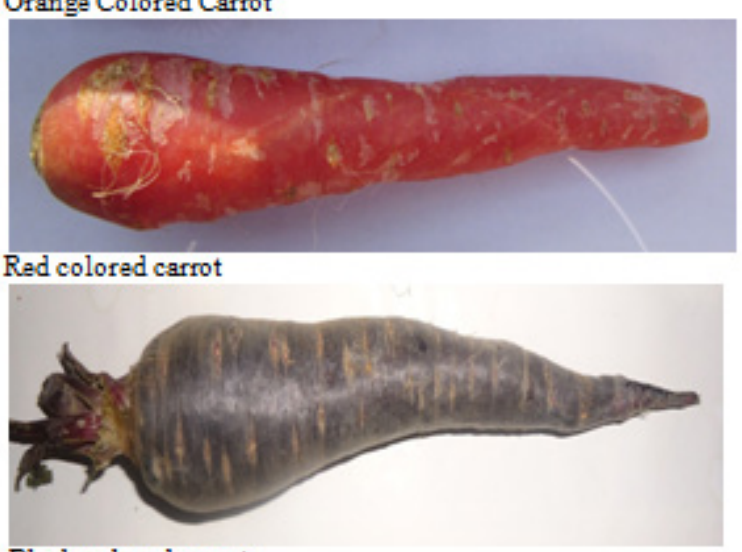

Black colored carrot

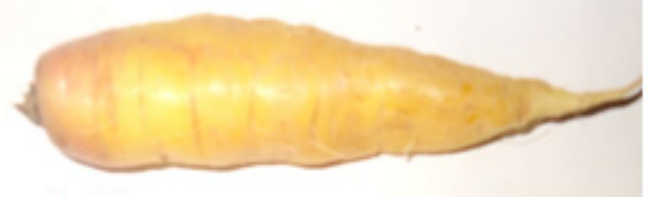

Yellow colored carrot

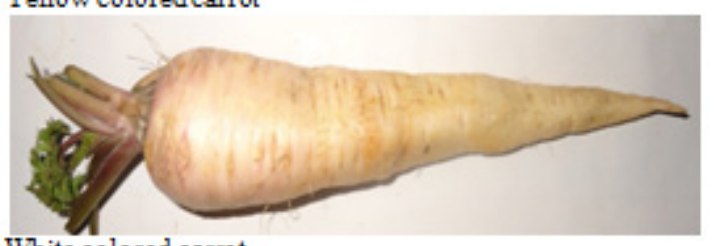

White colored carrot

Figure I Color diversity in carrots

\section{Conclusion}

The pigments that are present within carrot roots impart it with numerous functional properties in addition to color. The basic difference in molecular structure of pigments is responsible for presentation of a particular color by absorbing particular wave lengths of the visible spectrum. The color of carrots with predominance of $\alpha$-carotene is relatively fader than carrots with abundance of $\beta$-carotene, possible reason a lesser conjugated double bond. Singlet oxygen and radical scavenging ability of the pigments make it an effective antioxidant, and isolation and concentration of such chemicals can be used efficiently used for food supplementation and fortification.

\section{Acknowledgements}

None.

\section{Conflict of interest}

The authors declare that there is no conflict of interest.

\section{References}

1. Prasad K, Haq R, Bansal V, et al. Carrot secondary metabolites and their prospective health benefits. In: MW Siddiqui, Editors. Plant Secondary Metabolites: Stimulation, Extraction, and Utilization. Apple Academic Press, USA, 2016;107-194.

2. Haq R, Prasad K. Nutrition and processing aspects of carrot (Daucus carota)- A review. South Asian J Food Technol Environ. 2015;1:1-14.

3. Haq R, Kumar P, Prasad K. Physico-chemical, antioxidant and bioactive changes in cortex core sections of carrot (Daucus carota var. Pusa rudhira). Journal of Food Measurement and Characterization. 2016a;10(3):701708 .

4. Chu YF, Sun J, Wu X. Antioxidant and Antiproliferative Activities of Vegetables. J Agric Food Chem. 2003;50(23):6910-6916.

5. Koidis A, Rawson A, Tuohy M, et al. Influence of Unit Operations on the Levels of Polyacetylenes in Minimally Processed Carrots and Parsnips: An Industrial Trial. Food Chemistry. 2012;132(3):1406-1412.

6. Demmig Adams B, Gilmore AM, Adams WW. In Vivo Functions of Carotenoids in Higher Plants. FASEB J. 1996;10:403-412.

7. Vickie AV, Elizabeth WC. Essentials of Food Science. 3rd ed. Springer Science Business Media, LLC, New York, USA, 2007.

8. Haq R, Prasad K. Antioxidant activity, phenolic, carotenoid and color changes in packaged fresh carrots stored under refrigeration temperature. Journal of Food Measurement and Characterization. 2017;11(4):15421549 .

9. Sun M, Temelli F. Supercritical Carbon Dioxide Extraction of Carotenoids from CarrotUsing Canola Oil as a Continuous Co-Solvent. The Journal of Supercritical Fluids. 2006;37(3):397-408.

10. Haq R, Kumar P, Prasad K. Hot air convective dehydration characteristics of Daucus carota var. Nantes. Cogent Food Agric. 2015;1(1):1096184.

11. Haq R, Kumar P, Prasad K. Effect of microwave treatment on dehydration kinetics and moisture diffusivity of Asiatic Himalayan black carrot. Journal of the Saudi Society of Agricultural Sciences. 2016b.

12. Haq R, Kumar P, Prasad K. Influence of dehydration kinetics on moisture diffusivity, carotene degradation and nonenzymatic browning of pretreated and untreated carrot shreds. J Food Process Preserv. 2016c;41(2):e12785.

13. Britton G. Structure and Properties of Carotenoids in Relation to Function FASEB J. 1995;9(15):1551-1558.

14. Krinsky NI, Johnson EJ. Carotenoid Actions and their Relation to Health and Disease. Mol Aspects Med. 2005;26(6):459-516.

15. Gross J. Pigments in Vegetables-Chlorophylls and Carotenoids. Chapman \& Hall, New York, USA, 1991. 